Croatian Journal of Philosophy

Vol. XXI, No. 62, 2021

https://doi.org/ 10.52685/cjp.21.62.2

Received: August 19, 2020

Accepted: December 15, 2020

\title{
J. S. Mill on Higher Pleasures and Modes of Existence
}

TIM BEAUMONT

School of Foreign Languages, Shenzhen University, Shenzhen, PR China

The passage of Mill's Utilitarianism that sets out the condition in which one pleasure has a superior quality than another stokes interpretive controversy. According to the Lexical Interpretation, Mill takes one pleasure, $P_{1}$, to be of a superior quality than another, $P_{2}$, if, and only if, the smallest quantity of $P_{1}$ is more valuable than any finite quantity of $P_{2}$. This paper argues that, while the Lexical Interpretation may be supported with supplementary evidence, the passage itself does not rule out qualitative superiority without lexical dominance, as it only requires $P_{1}$ to be more valuable than any quantity of $P_{2}$ that it is possible for someone to experience. Some will object that this concession to opponents of the Lexical Interpretation still renders Mill's condition for qualitative superiority too demanding to be plausible. However, if Mill's qualitative rankings apply to higher-order pleasures taken in modes of existence as such rather than to the pleasures of different activities chosen from within these modes, the objection loses much of its force. One upshot is that Mill may have more to contribute to debates in contemporary population axiology than is usually acknowledged.

Keywords: John Stuart Mill; pleasure; qualitative hedonism; repugnant conclusion; population axiology; utilitarianism.

\section{Introduction}

Mill's Utilitarianism (1861) is generally taken to defend a hedonistic axiology according to which all and only pleasurable and painful experiences are bearers of final (or non-instrumental) value and disvalue respectively (X: 209; Beaumont 2018a, 2019). ${ }^{1} \mathrm{It}$ is also usually interpreted as rejecting a form of quantitative hedonism that takes the final value of a pleasure to be proportional to its "quantity", where this quantitative value is constituted by the product of two sub-values: intensity

${ }^{1}$ All references to Mill are to volume and page number of his (1963-1991). 
and duration (X: 213, 236; Crisp 1997: 32; Wilson 1990: 277-8). This is replaced with a form of qualitative hedonism that takes a pleasure's final value to be a function of its "quality" as well as its "quantity" (X: 211). Since Mill proceeds as if he accepts quantitative hedonism's conception of quantitative value, his qualitative hedonism is then taken to imply that the final value of pleasurable experiences is a function of their quality as well as their intensity and duration (Donner 1991: 41). On this view, the final (dis)value of a life is an aggregative function of the final value of its pleasures and the final disvalue of its pains, and the final (dis)value of a set (or population) of lives is an aggregative function of the final (dis)value of each individual life it contains. This paper treats the preceding interpretive framework as a working assumption and as its point of inception.

One interpretive controversy that arises therefrom concerns the veracity of the Lexical Interpretation of Mill's qualitative hedonism, which takes it to imply that one pleasure, $\mathrm{P}_{1}$, is of a superior quality than another, $\mathrm{P}_{2}$, if, and only if, the smallest quantity of $\mathrm{P}_{1}$ bears more final value than any finite quantity of $\mathrm{P}_{2}$ (proponents include: Brink 1997: 153; Crisp 1997: 40; and Riley 2003: 418). In contemporary population axiology, Derek Parfit also seems to endorse the Lexical Interpretation, and to intimate that it allows Mill to evaluate the aggregated pleasures of distinct populations in such a way as to avoid the:

"Repugnant Conclusion": ceteris paribus, given two possible substantial populations, $A$ and $B$, of a numerical size $n_{A}$ and $n_{B}$ respectively, such that the members of $A$ enjoy the highest quality of life possible but those of $B$ a quality of life that merely crosses the minimal threshold to make it worth living, the existence of $B$ may still be of greater final value provided that $n_{B}$ is sufficiently larger than $n_{A}$ for the aggregate welfare of $B$ 's population to outweigh that of $A$. (2004: 9-11, 17-20; 1984: 413-4) ${ }^{2}$

However, while many-but by no means all (Arrhenius, Ryberg, Tännsjö 2017: 2.8)—would see this as an advantage, it has not drawn many population axiologists to Mill's position (including Parfit himself, although see his 2016). Aside from an aversion to hedonism as such, the main reason for this may lie in the thought that the (supposedly) lexical character of Mill's qualitative hedonism could only generate this advantage at the cost of generating what we can refer to as the:

Extreme Conclusion: ceteris paribus, given one possible population, $C$, of a numerical size, $n_{C}$, whose members enjoy a good quality of life, and one possible person, $d$, who enjoys a quality of life that is of a marginally superior quality, the existence of $d$ would be of greater final value than the existence of $C$ regardless of how much greater $n_{C}$ is than 1 (see also Arrhenius, Ryberg, Tännsjö 2017: 2.1.1, 2.2). ${ }^{3}$

${ }^{2}$ Unlike Parfit's exposition, this one builds the final explanatory ('provided') clause into the conclusion itself (for the sake of convenience). It should also be noted that this reasoning assumes that the hedonist will cash out the notion of 'quality of life' in terms of the final (hedonic) value thereof.

${ }^{3}$ Some may also worry about the way in which a lexical qualitative hedonism will evaluate pains, but an examination of such concerns must be left for another study. 
Nevertheless, this Extreme Conclusion objection at the level of interpersonal evaluation-pertaining to the comparison of the final value of the lives of distinct people or beings (including sets thereof)- has been underexplored by Mill scholars as such (although see Miller 2010: 58). ${ }^{4}$

The main reason for this seems to be that most Mill scholars think that if the Lexical Interpretation were true, his qualitative hedonism would be falsified by an analogously 'extreme' implication at the antecedent intra-personal level of evaluation-pertaining to the comparison of the final value of different ways in which one person (or being) could live his or life-namely, that it can never be optimal for an individual to sacrifice hedonic quality for hedonic quantity (Anderson 1991: 9; Crisp 1997: 41; Hauskeller 2011: 433-5; Schaupp 2013: 275-6). ${ }^{5}$ For example, many will intuit that, ceteris paribus, while Life 1 below is hedonically preferable to Life 2 , Life 3 is hedonically preferable to either:

Life 1: with an abundance of 'higher quality' pleasure in books but no 'lower quality' pleasure in dessert.

Life 2: with no 'higher quality' pleasure in books and an abundance of 'lower quality' pleasure in dessert.

Life 3: with slightly less of the 'higher quality' pleasure in books than in Life 1 and as much of the 'lower quality' pleasure in dessert as Life 2 (adapted from Anderson 1991: 9).

Supposing the Lexical Interpretation were true, then, one might take this to show that, while Mill's distinction between quality and quantity is intuitive in terms of helping to explain why Life 1 is preferable to the comparatively 'repugnant' Life $2,{ }^{6}$ the requirement that quality lexically dominate quantity is too strong-or 'extreme'- to be plausible. ${ }^{7}$ Moreover, with this conclusion at hand, it has been claimed that the

${ }^{4}$ Those who doubt the commensurability of Mill's position with those of more recent philosophers may wish to consult Beaumont (2018b).

5 'Antecedent' because this is the level upon which Mill focuses when he offers the condition for qualitative superiority (X: 211, see below).

${ }^{6}$ For the distinction between 'repugnance' at the inter-personal and intrapersonal levels, see Arrhenius \& Rabinowicz (2015: 226-8) and Parfit (2016: 119).

${ }^{7}$ Anderson also concludes that Mill's appeal to 'quality' is an appeal to the value of something other than pleasure, and thus illicit given his official commitment to hedonism (1991: 10). Non-hedonists may be correct to think it is necessary to appeal to non-hedonic value-bearers to explain the comparative value of such lives (Schaupp 2013: 267; Skorupksi 1989: 299-303). However, this paper assumes that Mill is a consistent hedonist (see Beaumont 2019). Moreover, since it is designed to explore Mill's qualitative hedonism rather than question hedonism as such, it will assume that when two lives differ in final value, Mill is right to think it is in virtue of differences in the value of their pleasures. This much is compatible with the pleasures being valuable because they are pleasant (full hedonism) or because they are made valuable by non-hedonic value-makers (partial hedonism) (Crisp 1997: 26). The full hedonist view is also compatible with internalist or externalist conceptions of pleasure (Miller 2010: 35). This paper remains agnostic regarding these other debates concerning the character of Mill's hedonism (but see Beaumont (2019) for further discussion). 
Lexical Interpretation should be rejected on grounds of interpretive charity (Saunders 2016: 504; West 2004: 63-4).

This paper will re-examine the key passage of Utilitarianism in which Mill explains when, and why, one pleasure has a superior quality than another, and provide a technical taxonomy of some of the interpretive moves that must be made to defend the Lexical Interpretation (Section 2). It also defends two of these moves by arguing that the Lexical Interpretation is correct to interpret Mill as (1) offering a necessary, as well as a sufficient, condition for qualitative superiority (Section 3); and (2) taking the qualitative superiority of $\mathrm{P}_{1}$ to $\mathrm{P}_{2}$ to imply that the smallest quantity of $\mathrm{P}_{1}$ bears more final value than any finite quantity of $\mathrm{P}_{2}$ that a competent judge's "nature is capable of" (X: 211) (Section 4). However, without denying the truth of the Lexical Interpretation, the paper notes that it cannot rest on the passage in question alone, as any finite quantity of which a competent judge's nature is capable is less than any finite quantity as such..$^{8}$ In consequence, the strongest conclusion that the passage supports in isolation is that the smallest quantity of $\mathrm{P}_{1}$ must bear more final value than any (finite) quantity of $\mathrm{P}_{2}$ that could be experienced in a single life (Lifetime Interpretation).

Of course, given the way that the intra-personal version of the Extreme Conclusion objection is framed above, in terms of the choice between Lives 1-3, Mill would remain vulnerable to it given the Lifetime Interpretation. However, Section 5 of the paper argues that Mill's illustration of qualitative superiority with reference to different capacitybased "modes of existence" (X: 213) indicates that the objection may be ill-framed. Since modes of existence contain sets of pleasures (and pains), such as pleasures taken in books and dessert, pleasures taken in these sets of pleasures can be viewed as higher-order pleasures (or enjoyment) taken in the mode of existence as such. ${ }^{9}$ In consequence, if Mill's qualitative rankings are taken to apply at the higher-order level (Inter-Modal Interpretation), the supposed optimality of the trade-off between pleasure in books and dessert (as previously framed in terms of the choice of Life 3 over Life 1) would not challenge his position.

Given the Inter-Modal Interpretation, this optimality could be reframed in terms of an (intra-modal) preference for greater variety in the lower-order pleasures one experiences within a given mode of existence, rather than an occasional preference for lower over higher quality

${ }^{8}$ As highlighted by the possibility of inter-personal aggregation.

${ }^{9}$ West (2004: 64, 67, 69) also distinguishes between "first-order" and "secondorder" pleasures, on the one hand, and links the latter to Mill's "modes" or "manner[s] of existence" (X: 211, 213), on the other. While his use of these terms is perfectly legitimate, it is slightly different to the higher- and lower-order distinction in this paper. For example, whereas he seems to use "second-order pleasures" to refer to momentary pleasures taken in one's "self-image" as one enjoys a first-order pleasure in conformity therewith, this paper takes higher-order pleasures to consist of the extended pleasure or enjoyment of sets of momentary lower-order pleasures over time. 
pleasures as such. Moreover, this much is compatible with it remaining plausible that the value of the smallest quantity of the higher-order pleasure taken in a mode of existence incorporating reading outweighs that of the maximal quantity of pleasure that could be taken in a life devoid of the capacity for reading but replete with pleasure in dessert. In consequence, when combined with the Inter-Modal Interpretation, the Lifetime Interpretation (if not also the Lexical Interpretation) renders it plausible-as opposed to absurdly 'extreme'-to think that relations of qualitative superiority could emerge between the higher-order pleasures taken in those two modes of existence. Moreover, since the Lifetime Interpretation of Mill's qualitative hedonism does not automatically require Mill to embrace the Repugnant Conclusion, it raises the possibility that he found a way to navigate between 'repugnance' and 'extremity' at the inter-personal level that has yet to be fully explored.

\section{Mill on quality and quantity}

Mill sets out the condition for the qualitative superiority of one pleasure over another as follows:

[A] If I am asked, what I mean by difference of quality in pleasures, or what makes one pleasure more valuable than another, merely as pleasure, except its being greater in amount, there is but one possible answer. [B] Of two pleasures if there be one to which all or almost all who have experience of both give a decided preference, irrespective of any feeling of moral obligation to prefer it, that is the more desirable pleasure. [C] If one of the two is, by those who are competently acquainted with both, placed so far above the other that they prefer it, even though knowing it to be attended with a greater amount of discontent, and would not resign it for any quantity of the other pleasure which their nature is capable of, we are justified in ascribing to the preferred enjoyment a superiority in quality, so far outweighing quantity as to render it, in comparison, of small account. (X: 211)

The relationship between Passage A, on the one hand, and Passages $\mathrm{B}$ and $\mathrm{C}$, on the other, is confusing for several reasons. Firstly, while Passage A says that "there is but one possible answer" to its question, Passages B and C provide what look like different, and potentially conflicting, criteria. According to the interpretation that can be referred to as B-Sufficiency, Mill's one answer is given by Passage B, thus implying that it provides a sufficient condition for qualitative superiority. It then takes the more demanding condition constituted by the combination of Passage B and C to be sufficient for one pleasure to have much greater quality than another (Miller 2010: 58; Saunders 2011: 188-90; Schaupp 2013: 268; Schmidt-Petri 2003: 102-4). In contrast, according to the interpretation that can be referred to as C-Sufficiency, Passage B provides a necessary but insufficient condition for qualitative superiority, and thus Passages $\mathrm{B}$ and $\mathrm{C}$ provide the sufficient condition jointly (Anderson 1991: 9; Crisp 1997: 29; Hauskeller 2013: 433; Riley 2003: 410; Riley 2008: 63; Sturgeon 2010: 1711). ${ }^{10}$

${ }^{10}$ While this interpretation is labelled as ' $\mathrm{C}$-Sufficiency' for short, it is important to emphasize that it takes Mill's condition to incorporate the material from Passage 
A further interpretive puzzle pertaining to Passages B and C is whether Mill's sufficient condition for qualitative superiority is also a necessary condition thereof. The interpretations that can be referred to as B-Necessity and C-Necessity respectively both answer in the affirmative, with the former appending this claim to B-Sufficiency (Miller 2010: 58) and the latter to C-Sufficiency (Anderson 1991: 9; Crisp 1997: 29; Riley 2003: 410; Riley 2008: 63). ${ }^{11}$ In contrast, the interpretation that can be referred to as Anti-Necessity rejects both B-Necessity and C-Necessity on the grounds that Passage B or C respectively would only have committed Mill to the corresponding positions if he had rephrased them in a biconditional form (Schmidt-Petri 2003: 102-4; 2006: 166). ${ }^{12}$ The next two sections of the paper argue that Anti-Necessity can be set aside (Section 3), and that C-Sufficiency and Necessity should be endorsed instead (Section 4).

\section{An argument against anti-necessity}

One argument for C-Sufficiency is that, since Passage B only purports to provide a criterion for judging which of two pleasures, $\mathrm{P}_{1}$ and $\mathrm{P}_{2}$, is the "more desirable," and all agree that if $\mathrm{P}_{1}$ and $\mathrm{P}_{2}$ have the same qualitative value, $\mathrm{P}_{1}$ could be more desirable than $\mathrm{P}_{2}$ in virtue of superior quantitative value alone, the passage cannot provide a sufficient condition for qualitative superiority (Riley 2003: 412). Thus, the argument implies, to generate a sufficient condition Passage B must be supplemented with Passage C.

One reply on behalf of B-Sufficiency is that when Mill uses the clause "except its being greater in amount" in Passage A, following "what makes one pleasure $\left[\mathrm{P}_{1}\right]$ more valuable than another $\left[\mathrm{P}_{2}\right]$ ", he is not simply asserting that the criteria for qualitative difference must be distinct from the criteria for quantitative difference, but also indicating that the criteria given in Passage B should be read as presupposing that the quantities of $\mathrm{P}_{1}$ and $\mathrm{P}_{2}$ are already held fixed as equal (Miller 2010: 57-8). In consequence, the response maintains, once this implicit presupposition is read into Passage $B$, the greater value of $P_{1}$ as pleasure can only be explained by its superior quality, and hence Passage B can provide a sufficient condition after all (cf. Riley 2008: 62-3).

In the discussion that follows it will be important to distinguish between Mill's truth and justification conditions, which is to say the conditions in which he takes it to be the case that $\mathrm{P}_{1}$ is of a superior quality to $\mathrm{P}_{2}$, on the one hand, and the conditions in which he deems it justifiable to believe that this is so, on the other. The preceding defence

B as well, as the latter includes a "moral obligation" clause that is not explicitly restated in Passage C (see footnote 13).

${ }^{11}$ Miller seems to endorse B-Necessity when he says of the condition in Passage B that "its satisfaction is all that is required" (2010: 58).

${ }^{12}$ Schmidt-Petri only directs this objection at C-Necessity. However, ceteris paribus, its validity would undermine B-Necessity as well. 
of B-Sufficiency suggests that the best way to do this is to cash it out in terms of its attribution to Mill of the following claims:

OntologicalB-Sufficiency: if a quantity, $x$, of $\mathrm{P}_{1}$ is more valuable as pleasure than the same quantity, $x$, of $\mathrm{P}_{2}, \mathrm{P}_{1}$ is of a superior quality to $\mathrm{P}_{2}$.

Epistemic B-Sufficiency: if all or almost all competent judges prefer a quantity, $x$, of $\mathrm{P}_{1}$ as pleasure to the same quantity, $x$, of $\mathrm{P}_{2}$, the belief that $\mathrm{P}_{1}$ is of a superior quality to $\mathrm{P}_{2}$ is justifiable. ${ }^{13}$

This also allows B-Necessity to be cashed out in terms of the attribution to Mill of the corresponding pair of claims, Ontological B-Necessity and Epistemic B-Necessity, consisting of the preceding claims but with the direction of the conditionals reversed (see below).

In contrast, in the case of C-Sufficiency the corresponding theses would be as follows:

Ontological C-Sufficiency: if any quantity of $\mathrm{P}_{1}$, however small, is more valuable as pleasure than any quantity of $\mathrm{P}_{2}$ "which their nature is capable of" (Passage C), $\mathrm{P}_{1}$ is of a superior quality as pleasure to $\mathrm{P}_{2}$.

Epistemic C-Sufficiency: if all or almost all competent judges prefer any quantity of $\mathrm{P}_{1}$, however small, as pleasure to any quantity of $\mathrm{P}_{2}$ "which their nature is capable of", the belief that $\mathrm{P}_{1}$ is of a superior quality to $\mathrm{P}_{2}$ as pleasure is justifiable.

As before, this allows C-Necessity to be cashed out in terms of the attribution to Mill of the corresponding pair of claims, Ontological C-Necessity and Epistemic C-Necessity, consisting of the preceding claims but with the direction of the conditionals reversed (cf. Riley 2003: 418; Schmidt-Petri 2006: 166).

When formalized thus, it is possible to reduce, say, the epistemic dimension of the debate between B-Sufficiency and C-Sufficiency to the question of whether Mill would endorse Epistemic B-Sufficiency. ${ }^{14}$ Likewise, the debate over Anti-Necessity reduces to the question of whether it would be legitimate to: (1) infer Mill's commitment to Ontological and Epistemic B-Necessity from his commitment to Ontological and Epistemic B-Sufficiency respectively; and (2) infer Mill's commitment to Ontological and Epistemic C-Necessity from his commitment to Ontological and Epistemic C-Sufficiency respectively. In the remainder of this section, each of these inferences will be examined in turn.

Firstly, given the assumption that Mill is a qualitative hedonist, it should be uncontroversial that if one adopts Ontological B-Sufficiency, one must also adopt:

${ }^{13}$ These formulations oversimplify somewhat by abstracting from the "moral obligation" clause (Passage B) and the "discontent" clause (Passage C) (Anderson 1991: 9), the examination of which are left to another study. They also employ the "all or almost all" competent judges of (X: 211) rather than the mere "majority" thereof of (X: 213), but not much hangs on this for the argument that follows (see footnote 16).

${ }^{14}$ Note that the advocate of B-Sufficiency will take Mill to endorse Epistemic C-Sufficiency, whilst maintaining that C-Sufficiency as such is mistaken for taking Mill to reject Epistemic B-Sufficiency. 
OntologicalB-Necessity: if $\mathrm{P}_{1}$ is of a superior quality to $\mathrm{P}_{2}$, a quantity, $x$, of $\mathrm{P}_{1}$ is more valuable as pleasure than the same quantity, $x$, of $\mathrm{P}_{2}$.

After all, given a commitment to Ontological B-Sufficiency, and its attendant assumption that it is possible to compare and commensurate the hedonic quantities of pleasures of different hedonic qualities, Mill could only reject Ontological B-Necessity by denying that the qualities of pleasures affect their final value. However, that would be to abandon qualitative hedonism in favour of quantitative hedonism by implying that if $\mathrm{P}_{1}$ and $\mathrm{P}_{2}$ are equal in quantity, they are of equal final value.

Secondly, the epistemic transitions from endorsing either Epistemic B-Sufficiency, on the one hand, or Epistemic C-Sufficiency, on the other, to endorsing the following theses respectively should also be straightforward:

Epistemic B-Necessity: if the belief that $\mathrm{P}_{1}$ is of a superior quality to $\mathrm{P}_{2}$ is justifiable, all or almost all competent judges prefer a quantity, $x$, of $\mathrm{P}_{1}$ as pleasure to the same quantity, $x$, of $\mathrm{P}_{2}$.

Epistemic C-Necessity: if the belief that $\mathrm{P}_{1}$ is of a superior quality to $\mathrm{P}_{2}$ as pleasure is justifiable, all or almost all competent judges prefer any quantity of $\mathrm{P}_{1}$, however small, as pleasure to any quantity of $\mathrm{P}_{2}$ "which their nature is capable of" (Passage $\mathrm{C}$ ).

Of course, in each case the obvious objection will be that Mill could take an individual's hedonic beliefs to be justifiable when these beliefs defer to the preferences of all or almost all competent judges, without taking the beliefs to be unjustifiable insofar as they defy that verdict. ${ }^{15}$ For instance, one might think that Mill posits another mode of justification besides epistemic deference to the verdict of the competent supermajority, that is compatible with epistemic defiance thereof. However, shortly after Passage A-C, Mill rules out this possibility-by ruling out a justification for such epistemic defiance-when he declares that "[f]rom this verdict of the only competent judges, I apprehend there can be no appeal" (X: 213). ${ }^{16}$

This leaves the final controversy to be considered, over whether a justification for taking Passage A-C to support the attribution of Ontological C-Sufficiency to Mill would justify attributing the following to him as well:

Ontological C-Necessity: if $\mathrm{P}_{1}$ is of a superior quality as pleasure to $\mathrm{P}_{2}$, any quantity of $\mathrm{P}_{1}$, however small, is more valuable as pleasure than any quantity of $\mathrm{P}_{2}$ "which their nature is capable of" (Passage C),

${ }^{15}$ Such deference would not entail altering one's preference for $\mathrm{P}_{1}$ over $\mathrm{P}_{2}$ when almost all competent judges prefer $\mathrm{P}_{2}$ to $\mathrm{P}_{1}$, but rather refraining from taking one's preference to justify a belief that $\mathrm{P}_{1}$ is qualitatively superior to $\mathrm{P}_{2}$.

${ }^{16}$ A possible objection is that formulating the epistemic theses in terms of a "majority" of competent judges (see footnote 13) would have invalidated these transitions when: (1) the judges' preferences generate a tied qualitative verdict vis-à-vis two pleasures; and (2) it is nevertheless justifiable to believe that one is qualitatively superior. However, Mill gives no indication that (2) could be true given (1), even though it would not require an illicit counter-majoritarian appeal. Moreover, even if sound, the objection would not invalidate the transitions in standard cases in which there is a majority verdict. 
Of course, it would be "a mistake in propositional logic" (Schmidt-Petri: 2006: 170) to take the former to entail the latter directly. ${ }^{17}$ However, the validity of the inference does not depend upon Mill's introduction of an explicit biconditional in Passages B \& $\mathrm{C}$ as it is provided implicitly by Passage A's claim that Passage B or Passages B \& $\mathrm{C}$ provide(s) the "one possible answer" (emphasis added) to the question of when differences of quality obtain. After all, as Mill acknowledges while discussing causation in the System of Logic, if $\mathrm{Q}$ is the only condition that will suffice for R, Q is also necessary for R, and hence the satisfaction of the only sufficient condition for $\mathrm{R}$ can be inferred from $\mathrm{R}$ itself (VII: 438). ${ }^{18}$ In other words, given Passage $\mathrm{A}$, the sufficient condition for qualitative superiority provided by Passage B or Passage B \& C must also be a necessary condition thereof, and the Logic shows that Mill recognized the validity of this kind of inference. In consequence, the grounds of the debate shift to which of B-Sufficiency or C-Sufficiency should be endorsed in the first place.

\section{An argument for c-necessity}

An advocate of B-Sufficiency (and hence, given the argument of Section 3, B-Necessity) might object to C-Sufficiency (and hence C-Necessity) on the grounds that if Mill had taken his "one possible answer" (emphasis added) to be given by Passages B \& C jointly, he would have combined them into a single clause. However, this objection overlooks Mill's criticisms of Bentham's "intricate and involved style", which Mill claims to have rendered Bentham's "later writings books for the student only, not the general reader":

He [Bentham] could not bear, for the sake of clearness and the reader's ease, to say, as ordinary men are content to do, a little more than the truth in one sentence, and correct it in the next. (X: 114-5)

This passage is also grist to the mill of C-Sufficiency as it suggests that Mill could also view Passage B as a "sentence" containing "a little more than the truth," and thus requiring correction "in the next."19

That Passage $\mathrm{C}$ should be read this way is also suggested by a diary entry from 1854, in which Mill claims that:

[C*] Quality as well as quantity of happiness is to be considered; less of a higher kind is preferable to more of a lower. [B*] The test of quality is the preference given by those who are acquainted with both. (XXVII: 663)

Discussions of this passage tend to focus on whether it supports the Lexical Interpretation directly, by implying that it can never be opti-

${ }^{17}$ The following argument would also ground the three preceding inferences.

18 That is, Mill notes that the causal case in which Q is the "only possible cause" of R is also a logical case of Q if, and only if, R (VII: 438). Similarly, for Mill, seeing $a$ is not only sufficient for proof of $\alpha$ 's visibility, but also necessary qua constituting the only form of proof possible (X: 234).

${ }^{19}$ Note that in On Liberty Mill also formulates his "one very simple principle" cumulatively across two sentences, with an essential 'civilizational' scope restrictor added in the second (XVIII: 223). 
mal to sacrifice quality for quantity (Riley 2003: 415; Saunders 2011: 195; Schmidt-Petri 2006: 176). However, the passage could also support the Lexical Interpretation indirectly through what it reveals about the genealogy of Passages B and C. On the one hand, since Passage B* has a similar content to Passage $\mathrm{B}$, and Passage $\mathrm{C}^{*}$ has a similar content to Passage $\mathrm{C}$, but the diary entry reverses their order, we cannot simply take Passage B to provide Mill's sufficient condition because it is prior to Passage C. On the other, since Passage $\mathrm{B}^{*}$ elaborates and clarifies the condition introduced in Passage $\mathrm{C}^{*}$, the genealogical origin of Passage $\mathrm{C}$ also supports the claim that its purpose is to elaborate and clarify the condition introduced in Passage B. In consequence, an examination of Passage $\mathrm{C}^{*}$ and $\mathrm{B}^{*}$ weakens the case for B-Sufficiency, and strengthens that for C-Necessity, even before we consider how far the meaning of Passages $C^{*} \& B^{*}$ aligns with that of Passages B \& $C$.

To see the significance of the point, we need to view the diary passage in a broader context. In Utilitarianism Mill makes clear that happiness consists of a positive balance of pleasure over pain, but that if this positive balance is not somehow predicated upon higher quality pleasures, it can only be considered to be what the Logic describes as happiness in the "humble" as opposed to the "higher" sense of the term (VIII: 952; see also X: 211, Beaumont 2018a: 454). In consequence, by maintaining that "less of a higher kind" of happiness "is preferable to more of a lower", without adding any further quantitative qualifications (Beaumont 2019: 559 n.26; Riley 2003: 415; cf. Saunders 2011: 195), the diary entry supports the Lexical Interpretation by implying that the value of the higher quality pleasures that help to constitute the higher form of happiness, lexically dominates the value of the lower quality pleasures that help to constitute the lower form of happiness.

While defending C-Necessity, Jonathan Riley argues that Passage C should be read in the same lexical manner as the diary entry, by cashing out the quantity "which their nature is capable of" clause as "any finite amount" (2003: 418, emphasis added). In response, some object that, since some such finite quantities would transcend the capacities of a single person to experience them-for example, even at the intra-personal level one can imagine a quantity achieved by extending its duration into an afterlife, or by ratcheting up its intensity to a level requiring a super-human constitution (see also Crisp 1997: 23-5) — the "which their nature is capable of" clause introduces an implicit quantitative qualification that Riley's move ignores (Miller 2010: 57-8; Saunders 2011: 193; Sturgeon 2010: 1711 n.29). However, since the genealogy of the diary entry suggests that Passage $\mathrm{C}$ should be read as elaborating on Passage $\mathrm{B}$, on the one hand, and the diary entry's condition for qualitative superiority is much closer to that provided by C-Necessity, on the other, the most that the preceding objection could be claimed plausibly-as opposed to definitively - to show is that C-Necessity should not be extended into the Lexical Interpretation. For example, one might claim that, while the diary entry presents a lexical requirement for qualita- 
tive superiority, this was simply the original seed from which the position that Mill articulates in Passages B \& C grew, and it is the weaker condition for qualitative superiority found therein, which he opted to publish, that constitutes his considered position.

Without such an extension into the Lexical Interpretation, C-Necessity alone would imply that, for $\mathrm{P}_{1}$ to be of a superior quality to $\mathrm{P}_{2}$, the smallest quantity of $\mathrm{P}_{1}$ must bear more final value than any quantity of $\mathrm{P}_{2}$ of which the competent judges are capable of-which is to say, at least a lifetime's worth of $\mathrm{P}_{2}$-without requiring it to outvalue any finite quantity of $\mathrm{P}_{2}$ as such (the Lifetime Interpretation). To illustrate, consider Mill's famous comparison of the superior quality of "mental" pleasures, unique to the human mode of existence, and the "bodily" ones, to which a swine's mode of existence is entirely restricted (X: 211-3). In this case, C-Necessity implies that, ceteris paribus, a life with the smallest possible quantity of mental pleasure consistent with the human mode of existence bears more final value than a 'swinish' life that is replete with bodily pleasure but devoid of such mental pleasure. In contrast, the Lexical Interpretation generates the stronger implication that, ceteris paribus, the former life bears more final value than any number of lives of the second kind (Beaumont 2019: 571-5). In consequence, the answer to the question of whether C-Necessity should be construed in terms of the Lifetime Interpretation, or extended into the Lexical Interpretation, may be important for understanding the exact implications of Mill's axiology for his utilitarian animal ethics (Section 6).

\section{Hedonic quality and modes of existence}

Some deem the Lexical Interpretation to be uncharitable to Mill because the conditions for qualitative superiority it attributes to him are too demanding — or 'extreme' in their implications - to be plausible (Saunders 2016: 504; West 2004: 63-4). Since it could be claimed that this objection continues to apply in the case of C-Necessity alone-and thus the Lifetime Interpretation-its weaker requirement notwithstanding, it is worth outlining why its requirement may be much less demanding than it first appears.

Sometimes Mill writes about 'pleasures' of different qualities as if we can choose between them on a day-to-day basis. In these cases, he seems to use 'pleasure' to refer to short-term pleasurable experiences (X: 212-3), including the experience of activities (X: 235). However, his key examples of differences of hedonic quality involve comparisons of the pleasantness or enjoyableness of different experiential "modes of existence" (X: 213). For example, in addition to his comparison of the human and swinish modes mentioned above, he also compares the modes of the "intelligent human being" and the "fool", the "instructed person" and the "ignoramus", along with the mode of the person of "[moral] feeling and conscience" as contrasted with that of the person who is purely "selfish and base" (X: 211-2). 
As thus construed, a mode of existence consists of the experience of the multifarious potentialities born of the possession and exercise of a set of capacities over time. Given the taxonomy of experiences in Mill's Logic, different modes will include different kinds and levels of "sensations, thoughts, emotions, and volitions" (VII: 64). Moreover, some modes will require specific activities to exercise and sustain the capacities upon which they are predicated (X: 213). However, in the case of most human beings at least, a mode of existence will be much broader than any flash of consciousness or activity it incorporates (X: 215), in virtue of embodying the higher-order experience of experiencing many sensations, thoughts, emotions, and volitions over time, along with the sense of self that emerges in the process (XXXI: 138).

This much suggests that Mill could deem some of these higher-order experiences, consisting of sets of (lower-order) experiences of pleasures, to be higher-order pleasures that transcend the sum of their parts. After all, in the Logic Mill introduces the notion of "mental chemistry" to explain how comparatively complex feelings or experiences can be generated, as opposed to simply constituted, by sets or combinations of comparatively simple feelings or experiences (VIII: 854). If this were correct, Mill's focus on modes of existence would be explicable in terms of the fact that it is ultimately the higher-order pleasures taken therein to which his hedonism assigns its qualitative rankings (the Inter-Modal Interpretation).

To illustrate, consider the following passage from Utilitarianism:

A state of exalted pleasure lasts only moments, or in some cases, and with some intermissions, hours or days, and is the occasional brilliant flash of enjoyment, not its permanent and steady flame. Of this the philosophers who have taught that happiness is the end of life were as fully aware as those who taunt them. The happiness which they meant was not a life of rapture; but moments of such, in an existence made up of few and transitory pains, many and various pleasures, with a decided predominance of the active over the passive, and having as the foundation of the whole, not to expect more from life than it is capable of bestowing. (X: 215)

One way to read this passage is to take the "brilliant flash of enjoyment" to refer to a higher quality pleasure than that embodied in the "permanent and steady flame". However, the alternative proposed here is to read Mill as ascribing a high-level quality to the "enjoyment" of the "permanent and steady flame", and to take the "flash" to represent a brief increase in its intensity. On this view, the high-level quality is ascribed to an extended enjoyment of-or higher-order pleasure taken in-an "existence" with "moments" of "rapture", "many and various pleasures, with a decided predominance of the active over the passive" etc. ${ }^{20}$ Since Mill also describes this existence as including only "few and

${ }^{20}$ Crisp (1997: 27-8) notes that Mill's hedonism can only be understood properly when the term 'pleasure' is taken to include 'enjoyment'. Moreover, he also observes correctly that we can enjoy extended experiences that include some pain or suffering, such as struggling to climb a mountain. In consequence, one might take 
transitory pains", the quantitative preponderance of pleasure over pain it entails makes it a happy one (X: 210). Moreover, this is the "higher" form of happiness that Mill refers to in the Logic (VIII: 952) because the said preponderance incorporates higher-order pleasures of a relatively high quality (X: 211-2). In consequence, this account also aligns with the diary entry's reference to the "quality as well as quantity of happiness" (XXVII: 663; emphasis added) because it explains how the quality of the higher-order pleasures taken in a mode of existence can pass over into the quality of the happiness of that mode once its pains are also taken into account. ${ }^{21}$

Importantly, once C-Necessity is combined with the Inter-Modal Interpretation its condition for qualitative superiority becomes far less contentious at the intra-personal level. People may disagree over the size of the smallest possible durational quantity that $\mathrm{P}_{1}$ would have to take for it to constitute a genuine experience of, say, the human mode of existence, as opposed to an experience of nothing more than one of the fleeting sensations, thoughts, or activities that are performed therein. However, regardless of whether one judges the correct answer to be a day, a week, or longer, it would not be possible to refute Mill by claiming that a lifetime of swinish pleasure is more valuable than the pleasure of a snapshot of the consciousness of a human being (supposing this is actually true), ${ }^{22}$ as the quality of the pleasure of the human mode of existence would not be captured through such a comparison. ${ }^{23}$ Moreover, nor would it be possible to refute Mill by insisting that the more cerebral nature of the pleasure of reading is insufficient to ensure that it is always more valuable than the comparatively sensual pleasure of eating dessert, irrespective of how reading-rich and dessertpoor one happens to be at the time (cf. Anderson 1991: 9; Crisp 1997: 40-1). After all, if the pleasures of activities are indexed to the pleasure of the mode of existence in which they are undertaken-compare the

this to show that higher-order pleasures should be construed as pleasures taken in sets of lower-order pleasures and pains. However, that interpretive option has been rejected here for several reasons. Firstly, not all pains are enjoyable. Secondly, those which are enjoyable can be reconceived as pleasures using Mill's notion of complex ideas (VII: 57). And thirdly, Mill uses 'happiness' to encompass sets of pleasures and pains in which the former pre-dominate over the latter. In consequence, to take the higher-order pleasures, of which the Inter-Modal Interpretation claims 'quality' rankings to be predicated, to include pains, would be to muddy the waters between happiness and higher quality pleasure. In contrast, the version of the Inter-Modal Interpretation presented here clarifies the distinction whilst explaining the tightness of the connection between higher quality pleasure and higher quality happiness (see below).

${ }^{21}$ Hoag (1987: 418) refers to Mill's conception of happiness as a "higher-order [...] end of life".

${ }^{22}$ See also the example offered by Miller (2010: 58).

${ }^{23}$ In consequence, to employ the technical terms employed by Griffin (1986: 83-5), when the smallest possible unit of a pleasure-type is sufficiently large, the distinction between "trumping" and "discontinuity" may become less significant. 
mindset of Socrates eating dessert to that of a pig doing so-the difference between the pleasure of reading and eating dessert within the same of mode existence may be one of mere quantity, with the relative values depending upon the context of the choice. ${ }^{24}$

At an interpretive level, the preceding would also explain why Mill is more concerned to deny the existence of voluntary descent from a higher to a lower mode of existence than to insist that all highly cultivated people with strength of will are motivated to devote every drop of their time and energy to the most demanding intellectual, aesthetic, or moral activities (X: 213). That said, it is no doubt significant that one route to such descent could lie through choosing the likes of dessert over reading consistently, thus failing to sustain the capacities upon which the advanced mode is predicated. As a result, the Inter-Modal Interpretation can also explain Mill's occasional practice of referring to (intra-modal) activities as higher and lower pleasures, in terms of their role as indicators of the quality of the modes that people occupy, or to which these activities may lead them to fall or rise.

\section{Conclusion-Looking ahead}

This paper has provided a defence of C-Necessity, and thereby argued that Mill's qualitative hedonism should be interpreted in terms of the Lifetime Interpretation or the Lexical Interpretation. The choice between the two must ultimately be settled with reference to Mill's broader corpus. All that has been claimed here is that you cannot get to the Lexical Interpretation via (X: 211) alone.

The paper has also argued that, given the combination of the Lifetime and Inter-Modal Interpretations, the objection that Mill's condition for qualitative superiority is too 'extreme' or demanding loses much of its force at the intra-personal level. However, in doing so, the intent was not to suggest that this gives the Lifetime Interpretation much of an advantage, as the Lexical Interpretation can also be combined with the Inter-Modal Interpretation. Moreover, turning back to population axiology, advocates of the Lexical Interpretation may argue that, once it is combined with the Inter-Modal Interpretation, its extra vestigial demandingness gives it an interpretive advantage over the Lifetime Interpretation. After all, they may claim, it is the Lexical Interpretation alone that can explain how Mill's qualitative hedonism can avoid certain variants of the Repugnant Conclusion that prompted him to embrace qualitative hedonism in the first place. For example, they may argue that it is less plausible to interpret Mill as believing that the smallest quantity of the pleasure of the human mode is more valuable than that of the fullest pleasure taken in one swinish life only, than to interpret him as taking the former pleasure to outvalue that taken in any finite number of swinish lives (see Beaumont 2019: 571-5).

${ }^{24}$ Recall that Mill refers to "happiness" as "an existence made up of [...] many and various pleasures" (X: 215). See also West (2004: 62) and Saunders (2016: 515). 
In consequence, it is important to note that it is not (actually) selfevident that the Lifetime Interpretation would preclude such a judgment. After all, the Lifetime Interpretation can deny that Mill takes relations of qualitative superiority to entail lexical dominance, without denying that he takes any relations of qualitative superiority to rise to that level. On this view, Mill could take some qualitative differences to be far more significant than others, but for this to be manifest only once we cross the threshold from intra-personal to inter-personal evaluation. One reason this is important is that it is also far from self-evident that the Lexical Interpretation has an interpretive advantage at the inter-personal level when it comes to Mill's other axiological comparisons of modes of existence.

Recall that Mill also posits relations of qualitative superiority in the pleasures taken in the following modes: that of the intelligent being over the fool, that of the instructed person over the ignoramus, and that of the person of feeling and conscience over that of the person who is selfish and base. In the case of each of these pairs, is it more plausible to take Mill to believe that his qualitative superiority claim entails only that the smallest quantity of the former bears more final value than an entire lifetime of the latter (Lifetime Interpretation), or that he also takes it to entail that the smallest quantity of the former bears more value than that taken in any finite number of such lives (Lexical Interpretation)? When the choice between the Lifetime and Lexical Interpretation is framed thus, it is apparent that the Lexical Interpretation will be more prone to generate 'extreme' results, of doubtful consistency with Mill's own judgments, the further up the modal ladder of rank the (allegedly) lower quality pleasure of a given pair is located. That said, exactly how prone will depend upon an answer to a question that may be important for future research, namely, that of how Mill's individual comparisons of pairs of modes of existence are supposed to relate to each other. For example, is the qualitative superiority between the pleasure in the mode of existence of the instructed person and that of the ignoramus supposed to hold when the latter is also a person of feeling and conscience (supposing Mill takes that to be possible)? ${ }^{25}$ Ceteris paribus, an answer in the affirmative would make the Lexical Interpretation far less radical, and thus far less prone to generating 'extreme' results, than an answer in the negative.

Nevertheless, it is far from clear that the Lexical Interpretation can contain the danger when Mill's qualitative judgments are taken into consideration. ${ }^{26}$ In an intriguing letter to Thomas Hare written in 1865, Mill reports how reading Plato in Avignone, while staying there with his wife, is not quickening his "zeal" in his "own cause, as a candidate" for parliament:

${ }^{25}$ Consider (XVIII: 31; XIX: 390, 402).

${ }^{26}$ For one attempt at containment, resting on further interpretive claims the plausibility of which it is not possible to examine here, see Riley (2009: 131-3). 
It is an infinitely pleasanter mode of spending May to read the Gorgias and Theatetus under the avenue of mulberries which you know of, surrounded by roses and nightingales, than it would be to listen to tiresome speaking for half the night in the House of Commons. The only disagreeable thing here is having to choose between pleasures. (XVI: 1061, emphasis added)

Perhaps Mill is simply exaggerating here but, given the shortage of textual evidence with any potential to confirm the truth of the Lexical Interpretation (Schmidt-Petri 2006), it would be difficult for its advocates to dismiss the passage in this way, as opposed to taking it as the confirmation that Mill views qualitative differences between pleasures in terms of an infinite - or unbridgeable-gap in the value of their pleasantness. ${ }^{27}$ However, while advocates of B-Necessity may think that even the Lifetime Interpretation will generate an uncharitably 'extreme' implication in this case, the Lexical Interpretation is clearly in greater danger of doing so. After all, could Mill really be implying that, ceteris paribus, no number of lifetimes worth of the pleasures he could take in his parliamentary mode could bear more final value than the pleasures he could derive from a month in his philosophical mode with his wife at Avignone (cf. Parfit 2004: 18)? ${ }^{28}$

Of course, ultimately interpretations of Mill's qualitative hedonism also require evaluation in terms of whether, or how far, they can be made to cohere with his moral judgments. This can only be done with the aid of bridging principles predicated on specific interpretations of Mill's utility principle, on the one hand, and his theory of justice and rights, on the other. Since those interpretations will be highly contested (Cooper et al 1979; Lyons 1997), we should be careful to avoid jumping to simplistic conclusions about the moral implications that would flow from Mill's hedonism as such given the adoption of one interpretation thereof as opposed to another (Skorupski 2000: 259-60). At the same time, the examples above should make clear that there is at least the potential for the choice between the Lifetime and Lexical Interpretation to have a significant impact upon how far Mill's utilitarianism is taken to imply that differences in beings' modes of existence can generate differences in their moral status, and thus the attractiveness of his position for contemporary philosophers interested in population ethics as such. ${ }^{29}$

${ }^{27}$ For example, Riley's interpretation is that "any higher kind is infinitely more pleasant than any lower kind" (2009: 128).

${ }^{28}$ Here it may be worth noting a couple of other interpretive possibilities worth exploring: (1) that the size of the value gap is due to the fact that Mill is actually comparing a mode with a mere activity (this may be congenial to advocates of B-Necessity who take Mill to allow for some relations of qualitative superiority to rise to the level of lexical dominance (cf. Miller 2010: 56; see also Beaumont 2019: 571-5)); and (2) that the description of the parliamentary mode (or activity) as 'tiresome' implies that it is actually best conceived as a pain (this may be congenial to advocates of the Lexical Interpretation who want to limit its 'extremeness').

${ }^{29}$ I would like to thank Christoph Schmidt-Petri and Dale Miller for comments on and criticisms of an earlier version of this paper, as well as the two anonymous 


\section{References}

Anderson, E. 1991. “John Stuart Mill's Experiments in Living.” Ethics 102 (1): 4-26.

Arrhenius, G. Rabinowicz, W. 2015 "Value Superiority." In I. Hirose and J. Olson (eds.) The Oxford Handbook of Value Theory. Oxford University Press: 225-48.

Arrhenius, G. Ryberg, J. Tännsjö, T. 2017. "The Repugnant Conclusion." In E. Zalta (ed.) The Stanford Encyclopedia of Philosophy. https://plato. stanford.edu/entries/repugnant-conclusion

Beaumont, T. 2018a. "J. S. Mill's Hedonism: activism, experientialism, and eudaimonism." British Journal for the History of Philosophy 26 (3): 452-474.

Beaumont, T. 2018b. "A Perennial Illusion? Wittgenstein, Quentin Skinner's Contextualism, and the Possibility of Refuting Past Philosophers." Philosophical Investigations 41 (3): 304-28.

Beaumont, T. 2019. "J. S. Mill on Calliclean Hedonism and the Value of Pleasure.” Dialogue: Canadian Philosophical Review 58 (3): 553-578.

Brink, D. 1997. "Mill's Deliberative Utilitarianism." In D. Lyons (ed.) Mill's Utilitarianism: Critical Essays. Rowman \& Littlefield Publishers: 149_ 84.

Cooper, W. Nielson, K. Patten, S. 1979. New Essays on John Stuart Mill's Utilitarianism (ed.). Canadian Journal of Philosophy-Supplementary Volume.

Crisp, R. 1997. Mill on Utilitarianism. London: Routledge.

Donner, W. 1991. The Liberal Self: John Stuart Mill's Moral and Political Philosophy. Ithaca: Cornell University Press.

Griffin, J. 1986. Well-Being: Its Meaning, Measurement and Moral Importance. Oxford: Oxford University Press.

Hauskeller, M. 2011. "No Philosophy for Swine: John Stuart Mill on the Quality of Pleasures." Utilitas 23(4): 428-46.

Hoag, R. 1987. "Mill's Conception of Happiness as an Inclusive End." Journal of the History of Philosophy 25: 417-31.

Lyons, D. 1997. Mill's Utilitarianism: Critical Essays (ed.). Rowman \& Littlefield Publishers, Inc.

Mill, J. S. (1963-1991) Collected Works of John Stuart Mill (Vol. 1-33). Ed. John Robson. University of Toronto Press. https://oll.libertyfund.org/ people/john-stuart-mill

Miller, D. 2010. J. S. Mill: Moral, Social and Political Thought. London: Polity Press.

Parfit, D. 1984. Reasons and Persons. Oxford: Oxford University Press.

Parfit, D. 2004. "Overpopulation and the Quality of Life." In J. Ryberg and T. Tännsjö (eds.). The Repugnant Conclusion. Dodrecht: Kluwer Academic Publishers: 7-22.

Parfit, D. 2016. "Can We Avoid the Repugnant Conclusion?" Theoria 82: $110-27$.

Riley, J. 2003. “Interpreting Mill's Qualitative Hedonism.” The Philosophical Quarterly 53(212): 410-8.

referees for the Croatian Journal of Philosophy. Responsibility for the views expressed is purely my own. 
Riley, J. 2008. "What Are Millian Qualitative Superiorities?" Prolegomena 7 (1): 61-79.

Riley, J. 2009. "Millian Qualitative Superiorities and Utilitarianism, Part II." Utilitas 21(2): 127-43.

Saunders, B. 2011. "Reinterpreting the Qualitative Hedonism Advanced by J. S. Mill." Journal of Value Inquiry 45: 187-201.

Saunders, B. 2016. "Recent Critics of Mill's Qualitative Hedonism." Philosophy 91 (4): 503-521.

Schaupp, K. 2013. "Books Before Chocolate? The Insufficiency of Mill's Evidence for Higher Pleasures." Utilitas 25(2): 266-76.

Schmidt-Petri, C. 2003. "Mill on Quality and Quantity." The Philosophical Quarterly 53 (210): 102-4.

Schmidt-Petri, C. 2006. "On an Interpretation of Mill's Qualitative Hedonism." Prolegomena 5(2): 165-177.

Skorupski, J. 1989. John Stuart Mill. London: Routledge.

Skorupski, J. 2000. "Quality of Well-Being: Quality of Being." In R. Crisp and B. Hooker (ed.). Well-Being and Morality: Essays in Honour of James Griffin. Oxford: Clarendon Press.

Sturgeon, N. 2010. "Mill's Hedonism.” Boston Law Review 90: 1705-1729.

West, H. 2004. An Introduction to Mill's Utilitarian Ethics. Cambridge: Cambridge University Press.

Wilson, F. 1990. Psychological Analysis and the Philosophy of John Stuart Mill. University of Toronto Press. 